\title{
An Empirical Analysis of the Effect of Poverty on Health Care Utilization in Kenya
}

\author{
Peter K. Musyoka, PhD Candidate, \\ Julius Korir, PhD \\ Jacob Omolo, PhD \\ Charles C. Nzai, PhD
}

School of Economics, Kenyatta University, Kenya

Doi:10.19044/esj.2018.v14n22p101 URL:http://dx.doi.org/10.19044/esj.2018.v14n22p101

\begin{abstract}
Background: Good health is a fundamental human right, a valued asset, and a prerequisite for improved productivity. However, high poverty can lead to under utilization or lack of utilization of health care leading to poor health. Thus, poverty reduction and improvement of health care utilization are important in ensuring enjoyment of good health. Since 1982, poverty has remained above 40 per cent despite Kenya's commitment to poverty reduction. Kenya's health indicators have also not been impressive and health care utilization has remained low. Evidence shows that those who fell sick and reported lack of finances as the main reason for not seeking medical attention constituted 44 per cent, 38 per cent and 21.4 per cent in 2003, 2007 and 2013, respectively. These statistics point to poor health care utilization due to poverty. In Kenya, studies have concentrated on small segments of the population or parts of the country hence limiting generalization of the findings.
\end{abstract}

Objective: The objective of this paper was to determine the effect of poverty on health care utilization in Kenya.

Methods: The study used a Negative Binomial Regression and the 2013 Kenya Household Expenditure and Utilization Survey dataset. The study also used Two Stage Residual Inclusion approach and a Control Function Approach to test and control for potential endogeneity and unobserved heterogeneity problems, respectively.

Results: The estimation results showed that increase in wealth leading to reduction in poverty increased health care utilization. Other factors that had a positive effect on health care utilization were household size, early levels of education, and distance to the nearest health facility.

Conclusion: The study concludes that health care utilization is negatively affected by poverty other factors held constant. Thus, policies and strategies 
aimed at reducing poverty are needed. In particular the study recommends introduction of universal health care for all.

Keywords: Poverty, Health care utilization, Kenya

\section{Introduction}

Achieving the best health status possible is one of the most important social goals world-wide. This is because health is a human right as well as a valued asset necessary for improved productivity (Awiti, 2014). In case of poor health, an individual is faced with a wide variety of actions that he/she can undertake to improve health. Seeking health care is among the many actions that an individual may undertake. However, such an action may be influenced by the individual's ability to afford the health services (Asfaw, 2003; Awiti, 2014).

Since attaining her political independence in 1963, Kenya promised to address challenges of illiteracy, poverty and diseases (Republic of Kenya, 1965). Thus, Kenya put in place policies and programmes aimed at improved access and utilization of health care and poverty eradication. Among the poverty reduction strategies that the country adopted were strategy of rapid economic growth, job creation, adoption of technology, rural development focus, strategy of Structural Adjustment Programmes (SAPs), and basic needs strategy (Manda, Kimenyi, \& Mwabu, 2001; Misati \& Mngoda, 2012; Mureithi, 1988; Nafula, Onsomu, Mwabu, \& Muiruri, 2005). However, despite the government's effort to fight poverty, little has been achieved as poverty has remained above 40 per cent since 1982, rural areas been the most affected (Gakuru \& Mathege, 2012; Manda et al., 2001; Mureithi, 1988).

Regarding health care utilization, the Kenyan government has over time implemented various policies and initiatives aimed at addressing health care utilization challenges (Kimani, Mugo, \& Kioko, 2016). These broad initiatives are contained in various policy papers such as Kenya Health Policy Framework (KHPF, 1994-2010) and KHPF (2012-2030). Through the Kenya Household Health Expenditure and Utilization Surveys (KHHEUS) of 2003, 2007 and 2013, the government examined how utilization of health care has changed overtime. The KHHEUS reports showed that household members who reported illness but did not seek health care stood at 22.8 per cent in 2003. In 2007 and 2013, those who reported some sickness and failed to seek treatment stood at 16.7 per cent and 12.7 per cent, respectively, despite the government's efforts. Among the reasons given by those who reported sickness and failed to seek treatment were self medication, poor quality of service and distance to health care provider (Republic of Kenya, 2014). Individuals who felt sick and reported lack of finances as the main reason for not seeking health care stood at 21.4 per cent in 2013, a drop from 
37.7 per cent in 2007. In 2013, the most reported reason for not seeking health care was that illness was not considered to be serious enough to warrant medical attention (Republic of Kenya, 2014). A major concern is those people who reported illness and never sought treatment due to lack of finances.

Even though the government has been committed in issues of health care utilization, it remains a challenge and this could be due high poverty rates. For instance, children who were fully immunized in 2003 stood at 59 per cent. The rates for 2007 and 2012 were 73 per cent and 84.7 per cent, respectively (Republic of Kenya, 2008, 2012, 2013). The realized immunization levels were below the MDG target of 100 per cent by the year 2015. Further, the proportion of women who delivered assisted by skilled health care staff stood at 46 per cent in 2012 compared to a global target of 90 per cent by 2015 (Republic of Kenya, 2013).

Previous studies have attempted to explain the extent to which poverty affects health care utilization. However, the studies focused on small segment of the population in Kenya, or specific health services and small sections of the country (Akunga, Menya, \& Kabue, 2014; Kabubo-Mariara , Karienyeh, \& Kabubo, 2012; Muriithi, 2013; Mutua, Kimani-Murage, \& Ettarh, 2011; Mutunga, 2011; Ochako, Fotso, Ikamari, \& Khasakhala, 2011). Thus, findings of these studies may not be representative of the country, and hence cannot be generalized. The results of the effect of poverty on health care utilization have also been mixed.

Much of economic theory of the health analysis is based on the Grossman's human capital model (Grossman, 1972). The human capital model showed that every individual is born with some initial stock of health, which depreciates with age. However, the depreciation of health stock can be countered by investments like health care, diet, and exercise (Grossman, 1972). Thus, health care services are demanded in order to improve health status (Grossman, 1972, 2000). Other inputs individuals use to produce their own health include education, nutrition and lifestyle choices such as physical exercises, smoking and consumption of alcohol (Kimani, 2014; Mwabu, 2007; Namubiru, 2014). Therefore, the level of health is not treated as exogenous but depends on the amount of resources the individual allocates to the production of health.

Grossman (1972) argued that health care demand differs from other goods and services because it is a derived demand. Thus, demand for health services is derived from demand for good health. Good health increases individual's productivity and the total amount of time allocated on market and non-market activities. Therefore, health demanded is a consumption good, which enters directly into the individual's utility function. It is also an investment good, which increases the number of healthy days. The increased 
number of healthy days allows an individual to participate in both market and non-market activities, which in turn increase their earnings.

In the theory of consumer behavior, each individual has a utility function by which various combinations of goods and services that can be purchased are ranked. The theory assumes that individuals are rational. Therefore, individuals will choose a most preferred bundle of goods and services from the feasible set of consumption bundle allowed by their budget. Thus, individuals will buy goods and services that will generally increase their utility level (Grossman, 1972). The theory of human capital explains the motives for an individual to invest in human capital to raise productivity in both market and non-market sectors. The theory, therefore, highlights the role of human capital in producing earnings and commodities, which in turn feeds into the individual's utility function (Becker, 1967; Grossman, 1972, 2000).

Grossman (2000) also incorporated a household production function to explain the gap between health outcomes as an output and health care as an input. Grossman stressed that some output of household production function enters directly into the utility function. Further, Grossman (2000) distinguished goods and services from commodities, by presenting commodities as a function of goods and services, and consumer time. Grossman (2000), indicated that individuals buy health services and other goods to produce health which is a commodity. Health enters the utility function directly rather than healthcare being an input that enters directly into the utility function. Grossman's model remains unique in its approach to both theoretically and empirically conceptualise a complex demand for health and health care.

This study is anchored on the Grossman's human capital model. It makes use of count data models since the dependent variable (health care utilization) is measured using number of hospital visits. The main reason why Grossman's human capital is favored in this study is because it assumes that individuals maximise their utility through consumption of health care. The model also assumes that the household is the primary decision maker concerning use of health care. Thus, providers of health care have limited influence on the behaviour of health care users and hence the number of hospital visits they make.

\section{Methodology}

\subsection{Analytical Framework}

Borrowing from Adeoti and Awoniyi (2014), Ajakaiye and Mwabu (2007), Mwabu (2007) and (Mwabu, 2008), the study uses a standard economic model of household. In the model, utility function is maximized subject to health production and income constraints. The household utility 
$(U)$ depends on consumption of health related goods $(X)$, consumption of health neutral goods $(Y)$, and health status $(H)$ given as:

$U=u(X, Y, H)$

where $X$ is health related goods that have direct influence on the health status and also yields utility. Some of the health related goods include exercising, smoking, and engaging in risky behavior such as unprotected sex; $Y$ denotes the health neutral goods that have no direct effect on health status of the members such as clothing; and $H$ is health status of an individual.

From equation (1), let the production of health $(H)$ by an individual be described by the function given as:

$H=h(X, Z, P, G, \mu)$

where $Z$ is the purchased market inputs (health investment goods) such as medical services that affect individual health directly; $X$ is health related goods; $P$ are control variables such as insurance coverage, and employment status of individuals; $G$ are household characteristics and geographical characteristics such as marital status, age, residence, education, religion, and household size, and $\mu$ represents component of healthdue to genetic traits or environmental factors known to but not influenced by individuals or households (Ajakaiye \& Mwabu, 2007; Mwabu, 2007, 2008).

An individual maximizes equation (1) subject to health production function (2) and a household budget constraint given by equation (3)

$M=X P_{x}+Y P_{y}+Z P_{z}$

where $M$ is exogenous money income for the household, and $P_{x}, P_{y}, P_{z}$ are prices of health related goods $(X)$, health neutral goods $(Y)$, and health investments goods $(Z)$, respectively. From equations (1) and (2), health investment good $(Z)$ is assumed to be purchased only to improve individual's health so that it only enters the utility function (equation 1) through health production function $H$ given by equation (2).

The utility maximization problem can, therefore, be expressed in Lagrangian function as:

$L_{X, Y, Z, \lambda}=U\left\{X, Y, h(X, Z, P, G, \mu\}+\lambda\left(M-X P_{x}-Y P_{y}-Z P_{z}\right)\right.$

From (4), the first order necessary condition (FONC) for utility maximization can be given as:

$$
\begin{aligned}
& L_{X}=U_{X}\{X, Y, h(X, Z, P, G, \mu)\} * h_{X}(X, Z, P, G, \mu)-\lambda P_{x}=0 \\
& L_{Z}=U_{Z}\left\{X, Y, h(X, Z, P, G, \mu\} * h_{Z}(X, Z, P, G, \mu)-\lambda P_{z}=0\right. \\
& L_{Y}=U_{Y}\{X, Y, h(X, Z, P, G, \mu)\}-\lambda P_{y}=0 \\
& L_{\lambda}=M-X P_{x}-Y P_{y}-Z P_{z}=0
\end{aligned}
$$


Following Mwabu (2008) and Ajakaiye and Mwabu (2007), solving the FONCs simultaneously yields the health input demand functions of the optimal solutions to the individuals/households problem expressed as:

$X^{*}=D_{X}\left(P_{x}, P_{y}, P_{z}, M, P, G, \mu\right)$

$$
\begin{aligned}
& Y^{*}=D_{y}\left(P_{x}, P_{y}, P_{z}, M, P, G, \mu\right) \\
& Z^{*}=D_{z}\left(P_{x}, P_{y}, P_{z}, M, P, G, \mu\right)
\end{aligned}
$$

Following Kimani et al. (2016) and Fabbri and Monfardini (2003), this study estimated equation (11) using the Negative Binomial Regression Model (NBRM). In estimating models with count variables, the starting point is the standard Poisson regression model where the variable is assumed to have a Poisson distribution. Specifically for this study, the probability that health care utilization $(Y)$ takes a specific value $\left(y_{i}\right)$ is given by:

$$
\operatorname{Pr}\left[Y=y_{i} \mid X_{i}\right]=\frac{e^{-\omega_{i}} \omega_{i}^{y_{i}}}{y_{i} !}, y_{i}=0,1, \ldots
$$

Where $y_{i}$ is observed number of health facility visits (health care utilization), $\omega_{i}$ is the mean parameter, $X_{i}$ are the covariates of health care utilization, and $P_{r}$ represents probability. In most cases, the mean parameter $\omega_{i}$ is expressed in log-linear model (Greene, 2002) such that:

$\ln \omega_{i}=X_{i}^{\prime} \beta+\varepsilon_{i}$ or

$\omega_{i}=\exp \left(X_{i}^{\prime} \beta\right), \omega_{i}>0$

where $\varepsilon_{i}$ is individual heterogeneity in a cross-sectional data.

The Poisson distribution implies that the property of equi-dispersion: $E\left(y_{i} \mid x_{i}\right)=V\left(y_{i} \mid x_{i}\right)=\omega_{i}$ which is restrictive in empirical applications (Fabbri \& Monfardini, 2003), where, the conditional variance exceeds the conditional mean.

The distribution of $y_{i}$ conditioned on $X_{i}$ and $u_{i}$ (i.e $\varepsilon_{i}$ ) remains Poisson with conditional mean and variance $\omega_{i}$ :

$$
\operatorname{Pr}\left[y_{i} \mid X_{i}, u_{i}\right]=\frac{e^{-\omega_{i} u_{i}}\left(\omega_{i} u_{i}\right)^{y_{i}}}{y_{i} !} \text {. }
$$

Integrating $u_{i}$ out of the expression (14) produces the unconditional distribution of $y_{i}$. The formulation of this distribution is given by

$$
\operatorname{Pr}\left[y_{i} \mid X_{i}\right]=\frac{\Gamma\left(\theta+y_{i}\right)}{\Gamma\left(y_{i}+1\right) \Gamma(\theta)} \mu_{i}^{y_{i}}\left(1-\mu_{i}\right)^{\theta} \text {, where } \mu_{i}=\frac{\omega_{i}}{\omega_{i}+\theta} \text {. }
$$


which, is a form of the negative binomial model; where, $y_{i}$ is number of hospital visits made by individual $i$, and $X_{i}$ are covariates of health care utilization. The equivalent empirical equation model may be expressed as:

Visits $=\beta_{0}+\beta_{1}$ Povertystatus $+\beta_{i} X_{i}+\varepsilon$

However, poverty is potentially endogenous in health care utilization model. To address the endogeneity issue, this study used Two Stage Residual Inclusion (2SRI) approach to consistently estimate health care utilization. The approach involved two steps in which the first step was to estimate the endogenous variable model. Thus, in this study, the model of poverty status was first estimated. The poverty status of household $n$ was determined as follows:

$\operatorname{Pov}_{n}=\alpha_{1} P F_{n}+\alpha_{2} K_{n}+\varepsilon_{2 n}$

where PovS is poverty status of a household; $P F$ is predisposing factors such as age, sex, religion, household size, education level; $K$ is instrument variables; and $\varepsilon$ is the error term capturing unobservable factors influencing poverty status.

Use of 2SRI, however, has one challenge of getting appropriate instrument variables. However, in literature, variables that have been used as instruments for poverty status includes distance to the nearest NonGovernmental Organization (NGO) health unit, distance to the nearest market, time to get to water source (Namubiru, 2014), and proportion of children who are severely underweight in a region (Awiti, 2014). Dataset used in this study lacks such information, hence, called for innovation regarding variables that can serve as instruments. This study used the average number of households at the county level that have access to electricity. The choice of this variable was motivated by the fact that the average number of households at the county level that have access to electricity is not expected to influence how households utilize health care. However, access to electricity and poverty are deemed to be highly correlated. It is expected that households found in counties with lower electricity access should have a higher probability of being poor and the reverse should be true.

The chosen instrument variable needs to be valid. According to Awiti (2014) and Kimani et al. (2016), validity entails relevance, strength and exogeneity of an instrument variable. Relevance means that the instrumental variable should be strongly correlated to the endogenous variable. The strength of an instrumental variable implies that the magnitude of its coefficient should be large, while exogeneity means that the instrumental variable should be uncorrelated with the structural disturbance term.

Instrument variables should not be correlated with the structural error term. Thus, identification tests are needed to ascertain that such correlation 
does not exist. If there is over identification of a model due to instruments being more than the endogenous variables, then a test on whether the error term is uncorrelated with instruments is carried out. However, in case the model is just identified, test of over identification is not necessary. In this study, since only poverty status is endogenous and only one instrument is used, then there was no need of identification test.

The second stage involved estimation of the health care utilization model. In the stage, residuals from first stage and the endogegous variable were included as additional regressors. The addition of the residuals from the first stage was to control for variables that are not observable but are correlated with the endogenous variables. The act of including the residuals in the health care utilization model allowed the poverty status variable to be treated as if it was an exogenous covariate in the estimation (Kimani, 2014). The empirical model estimated in second stage was expressed as follows:

Visits $=\beta_{0}+\beta_{1}$ Povertystatus $+\beta_{2} \varepsilon_{2 n}+\beta_{i} X_{i}+\varepsilon_{1 n}$

where $\varepsilon$ is residuals from the first stage. If poverty status is exogenous in the health care utilization model, then $\beta_{2}$ will be equal to zero. Equation (16) will, therefore, be estimated using maximum likelihood method. $\varepsilon_{1}$ is a stochastic disturbance term.

If in this study, there is a non-linear interaction between unobserved factors and poverty status that cause the effect of poverty status on utilization of health care differ amongst the population subjects, then there could be a problem of unobserved heterogeneity (Awiti, 2014; Cameron \& Trivedi, 2005). To ascertain and solve the problem of unobserved heterogeneity, this study used the Control Function Approach (CFA) as proposed by Awiti (2014), and Ajakaiye and Mwabu (2007). The approach involves inclusion of interactions between the generalized residuals from poverty status model, and the poverty status variable in the health care utilization model. The estimated model was expressed as follows:

$$
\text { Visits }=\beta_{0}+\beta_{1} \text { Povertystatus }+\beta_{2} \hat{\varepsilon_{2 n}}+\beta_{3} \text { Povertystatus } * \hat{\varepsilon}_{2 n}+\beta_{i} X_{i}+\varepsilon_{1 n}
$$

\subsection{Data and Definition of Variables}

\subsubsection{Data}

The study used dataset from the 2013 Kenya Household Expenditure and Utilization Survey (KHHEUS). The dataset was collected by the Ministry of Health from a total of 33,675 households drawn from 1,347 clusters divided into $814(60 \%)$ rural and $533(40 \%)$ urban clusters. The 
survey covered 44 counties. Garissa, Mandera, and Wajir counties were not covered by the survey.

\subsubsection{Definition of Variables}

Health care utilization (HCU)-it is the use of health services by those who reported to have been sick. It is measured by the number of visits made to a health facility by an individual who reported to have been sick.

Age of individual (A)-it is the number of years of an individual at the time of survey. It is measured in years.

Sex (S)-it is the gender of the individual who reports to have been sick. It was coded $1=$ Male and $2=$ Female

Marital status (MS)-This captures whether an individual is married or not, categorized as 1=Never married, 2=Married, 3=Divorced/Separated/Widowed.

Education level (EL)-is the level of education completed by an individual and head of household. It was measured using $1=$ No education, 2=Primary, 3=Secondary and 4=College/University

Wealth index (WI)-it is the index capturing the standards of living of a family where an individual belongs based on asset ownership. It is a proxy for poverty status. The wealth index scores are continuous. Those with more assets have a higher score than those with less assets.

Household size (HS)-it is the number of members in a household measured using the actual number.

Religion (R)-it is the religion of individuals categorized as 1=Traditionalists/Atheists/Others, 2=Catholic, 3=Protestant, 4=Muslim,

Employment- It is the employment status of an individual. Dummy=1 if employed and 0, otherwise.

Distance to facility (DF)-it is the distance from the home of an individual to the nearest health facility measured in kilometers.

Residence (RS)-it is place of residence where the individual resides. It was $1=$ Rural, 2=Urban.

Waiting time- it is the number of hours that individuals spent in a health facility before they can be attended to.

Insurance cover-it is number of individuals with health insurance cover. Dummy=1 if yes, 0 otherwise

County average access to electricity-It is the average number of households that have access to electricity. The variable is continuous. Counties with more households with access to electricity have a higher mean score.

County average access to piped water-It is the average number of households that have access to piped water. The variable is continuous. Those counties with more households accessing piped water have a higher mean score. 


\subsection{Results}

Descriptive statistics of data used showed that household size ranged from 1 to 22 members with a mean of about six members. The individuals aged 34.8 years on average. In addition, on average individuals made 1.73 hospital visits and they had to wait for 0.8 hours on average before they could be treated. Wealth index ranged between -0.96 and 1.82 scores and had a mean of -0.13 scores. The low mean for wealth index is an indication that poverty level amongst households is high. The results also revealed that 64.04 per cent of the household members were residing in rural areas while the rest $(35.95 \%)$ were residing in urban areas. The results further showed that of all the household members, 53.58 per cent were females and 46.42 were males. In addition, results showed that 53.7 per cent of the household members were married, 36.7 per cent had never married and 9.6 per cent were divorced, separated or widowed. Regarding education, 16.33 per cent of the household members had no education, 45.4 per cent had primary level education, 29.4 per cent had secondary level education and 8.89 per cent had either college or university level education. Results further indicated that 56.65 per cent of the household members were employed while 43.44 were not employed. The results also showed that individuals residing within 1 kilometer from nearest health facility were 17 per cent while those living in 10 or more kilometers were 15.5 per cent.

\subsection{Effect of poverty on health care utilization in Kenya}

Several model selection tests were carried out before final estimation. Firstly, the test between Poisson regression model and negative binomial regression model was carried out. The test was done using Likelihood Ratio (LR) test. Secondly, in order to determine whether Zero Inflated Poisson (ZIP) was preferred to standard Poisson regression, a Vuong test was carried out (Baum, 2010). Results of the tests are presented in Table A1. The results indicate that the LR statistic is positive and statistically significant. Thus, the LR test rejected Poisson regression model in favor of the NBRM. The results of the Vuong test indicate that the Z-value was negative and statistically insignificant. Conclusion from the test was that Standard Poisson regression was preferred over ZIP. However, since the LR test had indicated presence of over-dispersion, and the results of Vuong test showed that over-dispersion was not due to presence of many zeros, the study opted for the NBRM. Since poverty is potentially endogenous in health care utilization model, the study used 2SRI and CFA methods to ascertain and control for potential endogeneity and unobserved heterogeneity (Ajakaiye \& Mwabu, 2007; Awiti, 2013; Kabubo-Mariara, Mwabu, \& Ndeng'e, 2009; Namubiru, 2014).

After model selection, the next step was to test for vaility and strength of the instrument used. Table A2 shows results for the test of 
validity, strength and relevance of the instrument. The results indicate that the instrument is highly correlated with the endogenous variable with a $\mathrm{P}$ value of 0.000 and is uncorrelated with the structural error term. Thus, average county access to electricity is a valid and strong instrument variable.

Results of the first stage of the 2SRI are similar to those presented in Table A2 (poverty status model). However, since the interest was only to get the residuals, the results of the first stage are not discussed here for brevity. Table 3.1 shows the baseline model (NBRM), the model controlling for endogeneity of poverty status (2SRI) and the model controlling endogeneity of poverty status and unobserved heterogeneity (CFA).

Table 3.1: Regression results of NBRM, 2SRI and CFA

\begin{tabular}{|c|c|c|c|}
\hline \multirow[t]{2}{*}{ Variable } & \multicolumn{3}{|c|}{ Dependent variable $=$ Number of hospital visits } \\
\hline & NBR Model & 2SRI Model & CFA Model \\
\hline Wealth index & $\begin{array}{c}0.035^{* *} \\
(0.015) \\
\end{array}$ & $\begin{array}{c}0.072 * * \\
(0.030) \\
\end{array}$ & $\begin{array}{c}0.076^{* *} \\
(0.030) \\
\end{array}$ \\
\hline Age & $\begin{array}{l}0.0004 \\
(0.002)\end{array}$ & $\begin{array}{l}0.0004 \\
(0.002)\end{array}$ & $\begin{array}{c}0.001 \\
(0.002)\end{array}$ \\
\hline Age Squared & $\begin{array}{c}7.97 \mathrm{e}-06 \\
(1.85 \mathrm{e}-05) \\
\end{array}$ & $\begin{array}{c}7.60 \mathrm{e}-06 \\
(1.86 \mathrm{e}-05) \\
\end{array}$ & $\begin{array}{c}6.58 \mathrm{e}-06 \\
(1.85 \mathrm{e}-05) \\
\end{array}$ \\
\hline \multicolumn{4}{|c|}{ Sex: Male(Reference) } \\
\hline Female & $\begin{array}{c}0.200 * * * \\
(0.013)\end{array}$ & $\begin{array}{c}0.198 * * * \\
(0.013) \\
\end{array}$ & $\begin{array}{c}0.198 * * * \\
(0.013)\end{array}$ \\
\hline \multicolumn{4}{|c|}{ Religion: Traditionalist/Atheist/Others(Reference) } \\
\hline Catholic & $\begin{array}{c}0.003 \\
(0.035)\end{array}$ & $\begin{array}{l}-0.003 \\
(0.036) \\
\end{array}$ & $\begin{array}{l}-0.005 \\
(0.036)\end{array}$ \\
\hline Protestant & $\begin{array}{c}0.070 * * \\
(0.034) \\
\end{array}$ & $\begin{array}{l}0.062^{*} \\
(0.035)\end{array}$ & $\begin{array}{l}0.060^{*} \\
(0.035)\end{array}$ \\
\hline Muslim & $\begin{array}{c}0.075^{* *} \\
(0.038) \\
\end{array}$ & $\begin{array}{l}0.070^{*} \\
(0.039) \\
\end{array}$ & $\begin{array}{l}0.069^{*} \\
(0.039) \\
\end{array}$ \\
\hline \multicolumn{4}{|c|}{ Marital Status: Never married(Reference) } \\
\hline Married & $\begin{array}{c}-0.177 * * * \\
(0.019) \\
\end{array}$ & $\begin{array}{c}-0.180 * * * \\
(0.020) \\
\end{array}$ & $\begin{array}{c}-0.179 * * * \\
(0.020) \\
\end{array}$ \\
\hline Divorced/separated/Widowed & $\begin{array}{c}-0.326 * * * \\
(0.027)\end{array}$ & $\begin{array}{c}-0.325^{* * *} * \\
(0.027)\end{array}$ & $\begin{array}{c}-0.325^{* * *} * \\
(0.270)\end{array}$ \\
\hline Log of household size & $\begin{array}{c}0.115 * * * \\
(0.010)\end{array}$ & $\begin{array}{c}0.120 * * * \\
(0.011)\end{array}$ & $\begin{array}{c}0.120 * * * \\
(0.011)\end{array}$ \\
\hline \multicolumn{4}{|c|}{ Education Level: No education(Reference) } \\
\hline Primary Education & $\begin{array}{c}0.052 * * * \\
(0.019)\end{array}$ & $\begin{array}{c}0.043 * * \\
(0.020)\end{array}$ & $\begin{array}{c}0.043 * * \\
(0.020)\end{array}$ \\
\hline Education & $\begin{array}{l}0.038^{*} \\
(0.022) \\
\end{array}$ & $\begin{array}{c}0.024 \\
(0.026) \\
\end{array}$ & $\begin{array}{c}0.024 \\
(0.026) \\
\end{array}$ \\
\hline College/university education & $\begin{array}{c}0.001 \\
(0.034) \\
\end{array}$ & $\begin{array}{l}-0.023 \\
(0.039) \\
\end{array}$ & $\begin{array}{l}-0.022 \\
(0.039) \\
\end{array}$ \\
\hline \multicolumn{4}{|c|}{ Employment Status: No (Reference) } \\
\hline Yes & $\begin{array}{c}0.001 \\
(0.015)\end{array}$ & $\begin{array}{l}0.0004 \\
(0.015)\end{array}$ & $\begin{array}{c}-0.0001 \\
(0.015) \\
\end{array}$ \\
\hline
\end{tabular}




\begin{tabular}{|c|c|c|c|}
\hline \multicolumn{4}{|c|}{ Area of residence: Rural (Reference) } \\
\hline Urban & $\begin{array}{l}-0.007 \\
(0.015)\end{array}$ & $\begin{array}{l}-0.023 \\
(0.018)\end{array}$ & $\begin{array}{l}-0.021 \\
(0.018)\end{array}$ \\
\hline Log of waiting time & $\begin{array}{c}-0.018 * * * \\
(0.005)\end{array}$ & $\begin{array}{c}-0.018 * * * \\
(0.005) \\
\end{array}$ & $\begin{array}{c}-0.018 * * * \\
(0.005) \\
\end{array}$ \\
\hline \multicolumn{4}{|c|}{ Distance to nearest health facility: $<1 K M$ (Reference) } \\
\hline $1-3 \mathrm{KM}$ & $\begin{array}{c}0.113 * * * \\
(0.017) \\
\end{array}$ & $\begin{array}{c}0.114 * * * \\
(0.017) \\
\end{array}$ & $\begin{array}{c}0.115 * * * \\
(0.017)\end{array}$ \\
\hline 4-5 KM & $\begin{array}{c}0.095 * * * \\
(0.021)\end{array}$ & $\begin{array}{c}0.095 * * * \\
(0.021)\end{array}$ & $\begin{array}{c}0.095 * * * \\
(0.021)\end{array}$ \\
\hline $6-9 \mathrm{KM}$ & $\begin{array}{c}0.177 * * * \\
(0.024)\end{array}$ & $\begin{array}{c}0.177 * * * \\
(0.024)\end{array}$ & $\begin{array}{c}0.178 * * * \\
(0.025)\end{array}$ \\
\hline $10+\mathrm{KM}$ & $\begin{array}{c}0.120 * * * \\
(0.022)\end{array}$ & $\begin{array}{c}0.118 * * * \\
(0.022)\end{array}$ & $\begin{array}{c}0.119 * * * \\
(0.022)\end{array}$ \\
\hline Poverty residual & & $\begin{array}{l}-0.048 \\
(0.034) \\
\end{array}$ & $\begin{array}{l}-0.036 \\
(0.034) \\
\end{array}$ \\
\hline $\begin{array}{l}\text { Interaction of wealth index and } \\
\text { poverty residuals }\end{array}$ & & & $\begin{array}{l}-0.062 * \\
(0.035) \\
\end{array}$ \\
\hline Constant & $\begin{array}{c}0.143 * * * \\
(0.055) \\
\end{array}$ & $\begin{array}{c}0.163 * * * \\
(0.057) \\
\end{array}$ & $\begin{array}{c}0.171 * * * \\
(0.058) \\
\end{array}$ \\
\hline Number of observations & 16,619 & 16,560 & 16,560 \\
\hline Pseudo R2 & 0.0138 & 0.0140 & 0.0140 \\
\hline Wald $\chi^{2}$ & $855.61 * * *$ & $857.65 * * *$ & $868.83 * * *$ \\
\hline $\operatorname{LR} \chi^{2}(2)$ & $707.79(0.000)^{\mathrm{a}}$ & $711.39(0.000)^{\mathrm{a}}$ & $717.05(0.000)^{\mathrm{a}}$ \\
\hline Linktest: hat & $0.935(0.00)^{\mathrm{a}}$ & $0.883(0.00)^{\mathrm{a}}$ & $0.777(0.00)^{\mathrm{a}}$ \\
\hline hat squared & $0.062(0.704)^{\mathrm{a}}$ & $0.111(0.491)^{\mathrm{a}}$ & $0.213(0.184)^{\mathrm{a}}$ \\
\hline Mean VIF & & 6.10 & \\
\hline
\end{tabular}

Note: $* * *, * *$ and $*$ denote statistical significance at 1 per cent, 5 per cent and 10 per cent levels of significance, respectively. (.)=Robust Standard Errors; $(.)^{\mathrm{a}}=\mathrm{P}$-value Source: Author's computation, Study Data, 2018

The estimation results of the second model, 2SRI, indicated that generalized residuals of poverty status were -0.048 and statistically insignificant. This suggested that poverty status was not endogenous in the health care utilization model. The third model, (CFA), indicated that the interaction of poverty status and its generalized residuals were -0.062 and statistically significant at 10 per cent level of significance. This showed presence of unobserved heterogeneity. Thus, the appropriate model for this study was the CFA regression since there was evidence of unobserved heterogeneity.

Estimation results presented in Table 3.1 shows that wealth index is positive and statistically significant. Thus, an increase in wealth leads to increased use of health care. This is not surprising since wealth is considered an important enabling factor that influences demand for health care. Wealthier individuals are in most cases educated, have well earning jobs and are well informed on where they can get quality health care and are also able 
to pay for the services (Kyegombe, 2003). The finding that wealth increases use of health care was consistent with earlier studies in Kenya (Kimani, 2014; Kimani et al., 2016; Ochako et al., 2011), which found that increase in wealth increases number of visits to hospitals.

Results of estimation also showed that the coefficient of sex was positive and statistically significant at 1 per cent significance level with a magnitude of 0.198. This implies that females were more likely to use health care compared to their male counterparts other factors being constant. The difference between females and males in the utilization of health care could be associated with reproductive and conditions specific to gender such as monthly periods associated with females only. In Kenya, maternal health services are free in government hospitals. This may partly explain the finding that females utilize health care more than males due to reproductive related services they use mostly related to sexual and reproductive health, prenatal care and maternal and child health. Anectodal evidence also shows that males are slow in seeking health care unless the illness is serious. The finding is consistent with those of Dias, Gama, Cortes, and de Sousa (2011) on Portugal, Skordis-Worrall, Hanson, and Mills (2011) on South Africa, and Zyaambo, Siziya, and Fylkesnes (2012) on Zambia who found that men are less likely to seek health care when they fall sick leading to less hospital visits.

Concerning religion, which was categorized as traditionalists/atheists/ others, Catholics, Protestants and Muslims, the estimation results showed that the coefficients for Protestants and Muslims were 0.060 and 0.069 , respectively. The coefficients were statistically significant at 10 per cent significance level. This implied that Protestants and Muslims were more likely to utilize health care than traditionalists/atheists/others, other factors being constant. This is an indication that Protestants and Muslims may believe in modern medicine compared to traditionalists who are conservative and will shun use of modern medicine even when seriously ill. This finding was consistent with those of Stephenson, Baschieri, Clements, Hennink, and Madise (2006) on Kenya, who found that protestants were more likely to visit a hospital for maternal health care compared to those who adhere to other beliefs.

Estimation results further showed that the divorced/separated/widowed and the currently married individuals were less likely to utilize health care compared to the unmarried ceteris paribus. The coefficients for the divorced/separated/widowed and the currently married were -0.179 and -0.325 , respectively. All the coefficients were statistically significant at one per cent level of significance. This finding indicates that currently married and divorced/separated/widowed probably have better health status compared to the unmarried individuals. The finding could as 
well suggest a higher opportunity cost of seeking health care for currently married and divorced/separated/widowed individuals who may be working hard to cater for their dependants. This finding is similar to those of Awiti (2014) in Kenya. The author found a negative relationship between marital status and health care utilization in Kenya.

The estimation results also indicated that the larger the household, the more the use of health care. The coefficient of the log of household size was positive with a magnitude of 0.120 . The coefficient was statistically significant at one per cent significance level. This finding could be because in larger households, individuals are more likely to fall sick, especially from communicable diseases due to congestion. Also, individuals from large households may suffer from nutrition related diseases such as malnutrition, especially if the household is poor. This high likelihood of individuals from large households falling sick may lead to more health care utilization. This study finding was consistent with those of Kimani et al. (2016) on Kenya. The author found that a ten per cent increase in household size led to 0.95 increase in the difference in logs of expected number of hospital visits.

According to estimation results, health care utilization increases with increase in education level. Compared to individuals with no education, those with primary level of education were more likely to use health care other factors being constant. The effect of education was positive for primary level of education with a magnitude of 0.043. The coefficient was statistically significant at 5 per cent significance level. This could be because educated individuals may understand better the benefits of good health and hence demand more health care. The educated individuals are also likely to have better jobs and earn income, which enables them to afford health care.

The estimation results further showed that the coefficient of log of waiting time was negative with a magnitude of -0.018 . The coefficient was statistically significant at one per cent significance level. This implied that long waiting time may discourage individuals from visiting hospitals for health care. This is mainly due to high opportunity costs associated with waiting while seeking health care. In this case, individuals who are in informal sector and those with unstable source of income are more likely to opt to go to work rather than spending many hours in hospitals seeking health care and lose their daily income. This finding contradicts those of Ali and Noman (2013) on Bangladesh and Kimani (2014) on Kenya. The authors found a positive relationship between waiting time and health care utilization.

Estimation results given in Table 3.1 further showed that distance to the nearest health facility had a positive effect on health care utilization. Distance to the nearest health facility was categorized in to four: 1) 1-3 Kilometers, 2) 4-5 Kilometers, 3) 6-9 Kilometers, and 4) more than 10 
Kilometers. The coefficients for categories 1 to 4 were $0.115,0.095,0.178$ and 0.119 , respectively. All the coefficients were statistically significant at 1 per cent significance level. Although this finding was not expected, the positive relationship between distance and health care utilization may suggest that distance is not a hindrance to health care utilization. This could be so especially if individuals are more concerned with quality of services offered or the cost of seeking health care at any given health facility. The finding on the relationship between distance and health care utilization is consistent with those of Awiti (2014) and Kimani et al. (2016) on Kenya who found a positive and statistically significant relationship between distance and health care utilization. However, the finding contradicts those of Awoyemi, Obayelu, and Opaluwa (2011) on Nigeria who found an inverse relationship between distance to nearest health facility and health care utilization.

Overall, the results presented and discussed revealed that increasing wealth increases health care utilization. In this study, wealth was a proxy for poverty status. Thus, it could be argued that, decrease in poverty increased health care utilization and vice versa. Other variables that were found to significantly affect health care utilization were sex, religion, marital status, household size, education level, waiting time and distance to nearest health facility.

\section{Conclusion:}

The estimation results indicates that health care utilization is negatively affected by poverty other factors held constant. This means that poor individuals are less likely to seek medication from health facilities when all other factors determining health care utilization are held constant. This study, therefore, concludes that reduction in poverty lead to increase in health care utilization. The other factors that were found to have positive effects on health care utilization were sex, household size, primary education level, and distance to the nearest health facility. The results also showed positive effects of being a protestant and being a Muslim on health care utilization. Furthermore, the results showed that being married and being divorced/separated/widowed and waiting time in a health facility had negative effect on health care utilization.

Therefore, considering one of the major determinants of good health, which is highly valued is health care, which defends on its affordability, then a key policy to enable majority poor access and use health services is to implement policies aimed at poverty reduction. This can be achieved through introduction of programs that empower the poor such as cash transfers and introduction of universal health care. Another hindrance to use of health care is long waiting time in health facilities. Thus, various health care providers 
should adopt technology and introduce queue management system to minimize time spent waiting to be attended to in a health facility.

The study also established that education had a positive and statistical significant effect on health care utilization. Thus, as the government puts more effort in reducing poverty, it should also ensure that people have access to education by promoting access to quality education. The government should construct more schools and equip them especially in the regions considered to have been marginalized for long. The government together with other education stakeholders and partners should also improve the teacher-student/pupil ratio, and ensure appropriate training and retraining of teachers.

\section{References:}

1. Adeoti, A. I., \& Awoniyi, O. A. (2014). Demand for Health Care Services and Child Health Status in Nigeria- A Control Function Approach. African Research Review, 8(1), 273. doi: 10.4314/afrrev.v8i1.18

2. Ajakaiye, O., \& Mwabu, G. (2007). The demand for reproductive health services: Frameworks of analysis. AERC, Nairobi.

3. Akunga, D., Menya, D., \& Kabue, M. (2014). Determinants of Postnatal Care Use in Kenya. African Population Studies, 28(3).

4. Ali, K. J., \& Noman, A. N. K. (2013). Determinants of demand for health care in Bangladesh: An Econometric Analysis. World Journal of Social Sciences, 3(6), 153-163.

5. Asfaw, A. (2003). How poverty affects the health status and the health care demand of households? The case of rural Ethiopia. Paper presented at the Staying Poor: Chronic Poverty and Development Policy, Institute for Development Policy and Management, University of Manchester, U.K. http://r4d.dfid.gov.uk/PDF/Outputs/ChronicPoverty_RC/Asfaw.pdf

6. Awiti, J. O. (2013). Essays on Health Determinants in Kenya. Unpublished $\mathrm{PhD}$ Thesis. School of Economics, University of Nairobi. Nairobi, Kenya.

7. Awiti, J. O. (2014). Poverty and health care demand in Kenya. BMC Health Services Research, 14(560). doi: 10.1186/s12913-014-0560-y

8. Awoyemi, T., Obayelu, O., \& Opaluwa, H. (2011). Effect of distance on utilization of health care services in rural Kogi State, Nigeria. Journal of human Ecology, 35(1), 1-9.

9. Baum, C. (2010). Models for Count Data and Categorical Response Data. Boston College and DIW, Berlin.

10. Becker, G. (1967). Human Capital and the personal distribution of income. Ann Arbor: University of Michigan. 
11. Cameron, A. C., \& Trivedi, P. K. (2005). Microeconomics: Methods and Applications. United States of America: Cambridge University Press.

12. Dias, S., Gama, A., Cortes, M., \& de Sousa, B. (2011). Healthcare-seeking patterns among immigrants in Portugal. Health \& social care in the community, 19(5), 514-521.

13. Fabbri, D., \& Monfardini, C. (2003). Public vs. private health care services demand in Italy. Giornale degli economisti e annali di economia, 93-123.

14. Gakuru, R., \& Mathege, N. (2012). Poverty, Growth, and Income distribution in Kenya: A SAM Perspective. AGRODEP Working Paper, 0001.

15. Greene, W. H. (2002). Econometric Analysis (5th ed.). New Jersey, Prentice Hall: Pearson Education, Inc.

16. Grossman, M. (1972). The demand for health; a Theoretical and Empirical Investigation. New York: National Bureau of Economic Research.

17. Grossman, M. (2000). The human capital model. Handbook of health economics, 1, 347-408.

18. Kabubo-Mariara , J., Karienyeh, M. M., \& Kabubo, F. M. (2012). Child Survival, Poverty and Inequality in Kenya: Does Physical Environment Matter? African Journal of Social Sciences, 2(1), 65-84.

19. Kabubo-Mariara, J., Mwabu, D., \& Ndeng'e, G. (2009). The Consequences of Fertility for Child Health in Kenya: Endogeneity, Heterogeneity and Application of the Control Function approach. Paper presented at the Center for the study of African Economies (CSAE) Conference 2009 on Economic Development in Africa, St Catherine's College, Oxford. http://www.csae.ox.ac.uk/conferences/2009-edia/papers/280mariara.pdf

20. Kimani, D. N. (2014). Out-of-Pocket Health Expenditures and Household Poverty: Evidence from Kenya Unpublished PhD Thesis. School of Economic, University of Nairobi. Nairobi, Kenya.

21. Kimani, D. N., Mugo, M. G., \& Kioko, U. M. (2016). An Econometric Analysis Of Health Care Utilization In Kenya. European Scientific Journal, 12(16).

22. Kyegombe, N. (2003). Health and chronic poverty, Background Paper to the Chronic Poverty Report 2004-5. Available at www.chronicpoverty.org

23. Manda, K. D., Kimenyi, M. S., \& Mwabu, G. (2001) A Review of Poverty and Antipoverty Initiatives in Kenya

24. KIPPRA Working Paper: Vol. 3. Nairobi, Kenya: KIPPRA. 
25. Misati, J., \& Mngoda, D. (2012). Re-Visioning Kenya's Social Development Agenda for Industrialization and Sustainable Development. Paper presented at the Scientific Conference Proceedings.

26. Mureithi, P. L. (1988). Development Planning in Kenya. In M. Urrutia \& S. Yukawa (Eds.), Development Planning in Mixed Economies (pp. 198-219). Tokyo, Japan: The United Nations University.

27. Muriithi, M. K. (2013). The determinants of health seeking behaviour in a Nairobi slum, Kenya. European Scientific Journal, 9(8), 151164.

28. Mutua, M. K., Kimani-Murage, E., \& Ettarh, R. R. (2011). Childhood vaccination in informal urban settlements in Nairobi, Kenya: Who gets vaccinated? BMC Public Health, 11(6).

29. Mutunga, C. J. (2011). Environmental determinants of child mortality in Kenya Health Inequality and Development (pp. 89-110): Springer.

30. Mwabu, G. (2007). Health Economics for Low-Income Countries. Center Discussion Paper, 955. http://www.econ.yale.edu/growth_pdf/cdp955.pdf

31. Mwabu, G. (2008). The Production of Child Health in Kenya: A Structural Model of Birth Weight. Journal of African Economies, $18(2), 212-260$.

32. Nafula, N. N., Onsomu, E. N., Mwabu, G., \& Muiruri, S. (2005) Review of Policy Options for Poverty Reduction in Kenya. KIPPRA Discussion Paper: Vol. 49. Nairobi, Kenya: KIPPRA.

33. Namubiru, L. (2014). Effect of Household Poverty on Women's Fertility and Child Nutritional Status in Uganda. Unpublished PhD Thesis. School of Economics, University of Nairobi.

34. Ochako, R., Fotso, J.-C., Ikamari, L., \& Khasakhala, A. (2011). Utilization of maternal health services among young women in Kenya: Insights from the Kenya Demographic and Health Survey, 2003. BMC Pregnancy and Childbirth, 11(1).

35. Republic of Kenya. (1965). African Socialism and its Application to Planning in Kenya. Nairobi, Kenya: Government Printer.

36. Republic of Kenya. (2008). Kenya Vision 2030: First Medium Term Plan, 2008-2012. Nairobi, Kenya: Ministry of State for Planning, National Development and Vision 2030.

37. Republic of Kenya. (2012). Health Sector Working Group Report. Medium Term Expenditure Framework (MTEF) for the period 2013/14-2015/16. Nairobi, Kenya: Ministry of Health. 
38. Republic of Kenya. (2013). Kenya Vision 2030: Second Medium Term Plan, 2013-2017. Nairobi, Kenya: Ministry of Devolution and Planning.

39. Republic of Kenya. (2014). Kenya Household Health Expenditure and Utilisation Survey 2013. Nairobi, Kenya: Ministry of Health.

40. Skordis-Worrall, J., Hanson, K., \& Mills, A. (2011). Estimating the demand for health services in four poor districts of Cape Town, South Africa. International Health, 3, 44-49.

41. Stephenson, R., Baschieri, A., Clements, S., Hennink, M., \& Madise, N. (2006). Contextual influences on the use of health facilities for childbirth in Africa. American journal of public health, 96(1), 84-93.

42. Zyaambo, C., Siziya, S., \& Fylkesnes, K. (2012). Health status and socio-economic factors associated with health facility utilization in rural and urban areas in Zambia. BMC Health Services Research, 12(1), 389 .

\section{Appendix}

Table A1: Poisson, NBRM and ZIP Models Selection based on Vuong and LR tests

\begin{tabular}{|c|c|c|c|c|c|c|}
\hline \multirow[b]{3}{*}{ Variable } & \multicolumn{2}{|c|}{ Poisson Model } & \multicolumn{2}{|c|}{ NBRM Model } & \multicolumn{2}{|c|}{ ZIP Model } \\
\hline & \multicolumn{6}{|c|}{ Dependent Variable=Number of visits } \\
\hline & Coeff. & $\mathbf{P}>\mathbf{Z}$ & Coeff. & $\mathbf{P}>\mathbf{Z}$ & Coeff. & $\mathbf{P}>\mathbf{Z}$ \\
\hline Wealth Index & $0.037 * *$ & 0.022 & $0.037 * *$ & 0.022 & $0.037 * *$ & 0.015 \\
\hline Age & 0.0005 & 0.802 & 0.0005 & 0.811 & 0.0004 & 0.804 \\
\hline Age Squared & $7.42 \mathrm{e}-06$ & 0.691 & $7.63 \mathrm{e}-06$ & 0.682 & $7.42 \mathrm{e}-06$ & 0.711 \\
\hline \multicolumn{7}{|c|}{ Insurance Cover (Not insured $=$ Reference) } \\
\hline Insured & -0.009 & 0.620 & -0.09 & 0.618 & -0.009 & 0.603 \\
\hline Log of waiting time & $-0.018 * * *$ & 0.001 & $-0.018 * * *$ & 0.001 & $-0.018 * * *$ & 0.000 \\
\hline \multicolumn{7}{|c|}{ Gender (Male $=$ Reference $)$} \\
\hline Female & $0.200 * * *$ & 0.000 & $0.200 * * *$ & 0.000 & $0.200 * * *$ & 0.000 \\
\hline \multicolumn{7}{|c|}{ Religion (Traditionalist/Atheist/Others=Reference) } \\
\hline Catholic & 0.003 & 0.922 & 0.003 & 0.922 & 0.003 & 0.932 \\
\hline Protestant & $0.070 * *$ & 0.042 & $0.070^{*}$ & 0.042 & $0.070^{*}$ & 0.076 \\
\hline Muslim & $0.075^{*}$ & 0.051 & $0.075^{*}$ & 0.051 & $0.075^{*}$ & 0.088 \\
\hline Log of household size & $0.115 * * *$ & 0.000 & $0.115 * * *$ & 0.000 & $0.115 * * *$ & 0.000 \\
\hline \multicolumn{7}{|c|}{ Distance to nearest health facility: $<1$ KM (Reference) } \\
\hline $1-3 \mathrm{KM}$ & $0.114 * * *$ & 0.000 & $0.113 * * *$ & 0.000 & $0.114 * * *$ & 0.000 \\
\hline 4-5KM & $0.096 * * *$ & 0.000 & $0.095 * * *$ & 0.000 & $0.096 * * *$ & 0.000 \\
\hline $6-9 \mathrm{KM}$ & $0.177 * * *$ & 0.000 & $0.177 * * *$ & 0.000 & $0.177 * * *$ & 0.000 \\
\hline $10+$ & $0.121 * * *$ & 0.000 & $0.120 * * *$ & 0.000 & $0.121 * * *$ & 0.000 \\
\hline \multicolumn{7}{|c|}{ Marital status (Never Married =Reference) } \\
\hline Married & $-0.177 * * *$ & 0.000 & $-0.177 * * *$ & 0.000 & $-0.177 * * *$ & 0.000 \\
\hline Divorced/ & $-0.327 * * *$ & 0.000 & $-0.326 * * *$ & 0.000 & -0.327 & \\
\hline
\end{tabular}


separated/

Widowed

Education Level (No education=Reference)

\begin{tabular}{|c|r|r|r|r|r|r|}
\hline Primary Education & $0.052 * * *$ & 0.006 & $0.052 * * *$ & 0.006 & $0.052 * * *$ & 0.007 \\
\hline Secondary Education & $0.039 *$ & 0.082 & $0.039 *$ & 0.082 & $0.039 *$ & 0.091 \\
\hline College/university education & 0.004 & 0.903 & 0.004 & 0.900 & 0.004 & 0.898 \\
\hline Employment status (1=employed; 0 otherwise) & 0.001 & 0.936 & 0.001 & 0.939 & 0.001 & 0.935 \\
\hline
\end{tabular}

Area of residence (Rural $=$ Reference)

\begin{tabular}{|c|c|c|c|c|c|c|}
\hline Urban & -0.007 & 0.649 & -0.007 & 0.650 & -0.007 & 0.625 \\
\hline Constant & $0.142 * * *$ & 0.010 & $0.143 * * *$ & 0.010 & $0.142 * *$ & 0.014 \\
\hline Number of Observations & \multicolumn{2}{|c|}{16,619} & \multicolumn{2}{|c|}{16,619} & \multicolumn{2}{|c|}{16,619} \\
\hline Zero Observations & \multicolumn{2}{|l|}{-} & \multicolumn{2}{|l|}{-} & \multicolumn{2}{|l|}{89} \\
\hline Non-Zero Observations & \multicolumn{2}{|l|}{-} & \multicolumn{2}{|l|}{-} & \multicolumn{2}{|c|}{16,530} \\
\hline Pseudo R2 & \multicolumn{2}{|c|}{0.0142} & \multicolumn{2}{|c|}{0.0138} & \multicolumn{2}{|l|}{-} \\
\hline Wald $\chi^{2}(21)$ & $859.2 * * *$ & 0.000 & $859.78 * * *$ & 0.000 & - & - \\
\hline $\operatorname{LR} \chi^{2}(21)$ & - & - & - & - & $728.04 * * *$ & 0.000 \\
\hline Likelihood Ratio Test (Poisson Vs. NBRM) & - & - & $6.49 * * *$ & 0.005 & - & - \\
\hline Vuong Test of ZIP Vs. Standard Poisson & - & - & - & - & $Z=-0.03$ & 0.514 \\
\hline Linktest: hat & $0.940 * * *$ & 0.000 & $0.940 * * *$ & 0.000 & - & - \\
\hline hat squared & 0.057 & 0.724 & 0.057 & 0.729 & - & - \\
\hline
\end{tabular}

Note: $* * *, * *$, and $*$ denote statistical significance at 1 per cent, 5 per cent and 10 per cent, levels of significance, respectively.

Source: Author's computation, Study Data, 2018

Table A2: Validity test of instrumental variable in health care utilization model

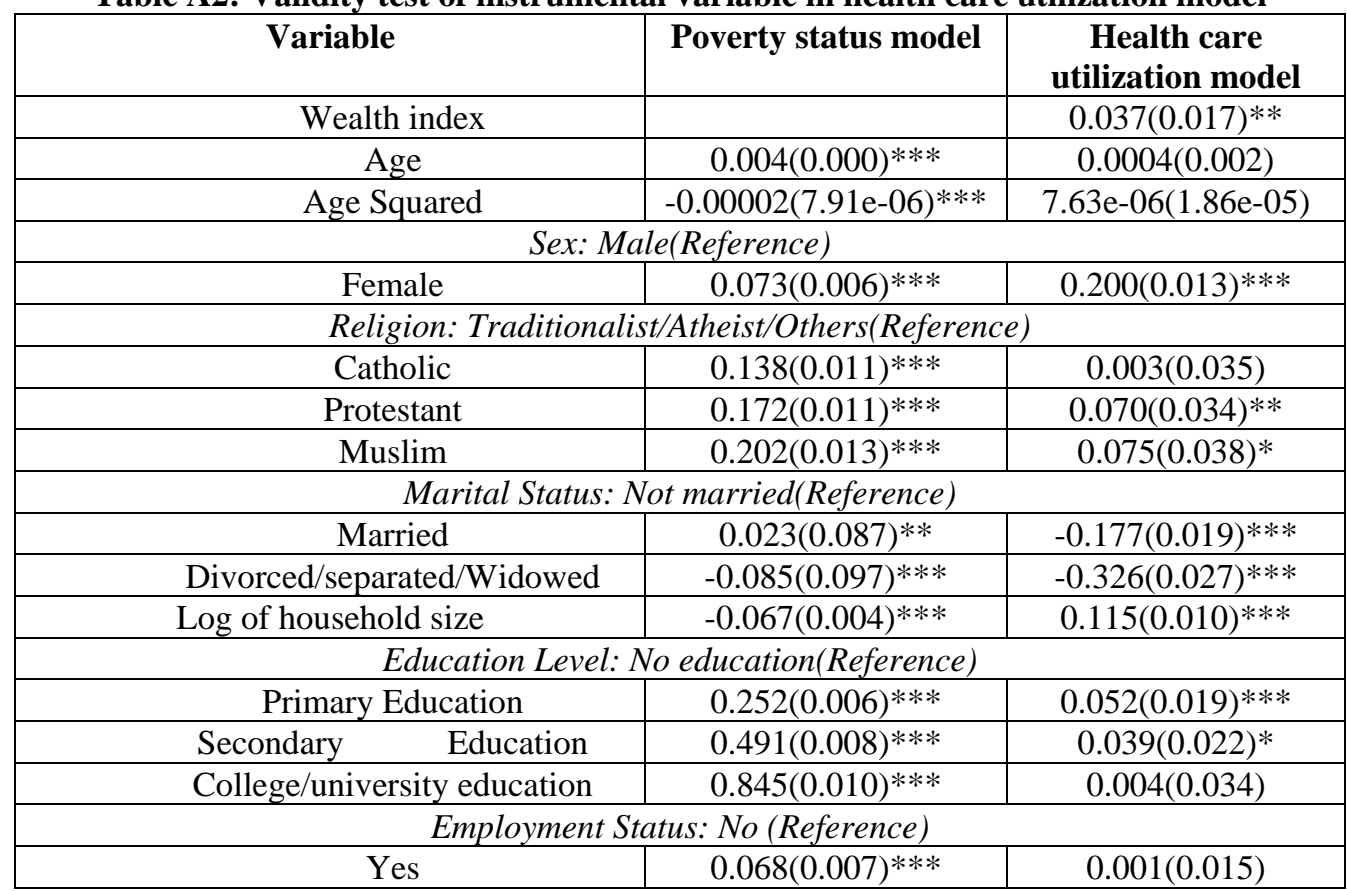




\begin{tabular}{|c|c|c|}
\hline \multicolumn{3}{|c|}{ Area of residence: Rural (Reference) } \\
\hline Urban & $0.348(0.005)^{* * *}$ & $-0.007(0.015)$ \\
\hline \multicolumn{3}{|c|}{ Insured: Not insured (Reference) } \\
\hline Insured & & $-0.009(0.019)$ \\
\hline Log of waiting time & & $-0.018(0.005)^{* * *}$ \\
\hline \multicolumn{3}{|c|}{ Distance to nearest health facility: $<1 \mathrm{KM}$ (Reference) } \\
\hline $1-3 \mathrm{KM}$ & & $0.113(0.017)^{* * *}$ \\
\hline $4-5 \mathrm{KM}$ & & $0.095(0.021) * * *$ \\
\hline $6-9 \mathrm{KM}$ & & $0.177(0.024) * * *$ \\
\hline $10+\mathrm{KM}$ & & $0.120(0.022)^{* * *}$ \\
\hline \multicolumn{3}{|c|}{ County average access to electricity: No (Reference) } \\
\hline Yes & $0.633(0.022)^{* * *}$ & $0.001(0.042)$ \\
\hline \multicolumn{3}{|c|}{ County average access to piped water: No (Reference) } \\
\hline Yes & $0.174(0.018)^{* * *}$ & \\
\hline Constant & $-0.955(0.022) * * *$ & $0.143(0.057)^{* *}$ \\
\hline Number of observations & 28,968 & 16,619 \\
\hline R-Squared/Pseudo R2 & R-Squared $=0.5373$ & Pseudo R2=0.0138 \\
\hline $\mathrm{F}(16,28951)$ & $2413.96 * * *$ & \\
\hline Wald $\chi^{2}(22)$ & & $859.85(0.000)^{\mathrm{a} * * *}$ \\
\hline Linktest: hat & $0.9987(0.000)^{\mathrm{a} * * *}$ & $0.9404(0.000)^{\mathrm{a} * * *}$ \\
\hline hat squared & $0.0054(0.620)^{\mathrm{a}}$ & $0.0568(0.729)^{\mathrm{a}}$ \\
\hline Mean VIF & 6.68 & 5.45 \\
\hline
\end{tabular}

Note: $* * * * *$ and $*$ indicates statistical significance at 1 per cent, 5 per cent and 10 per cent levels of significance, respectively. (.)=Robust Standard Errors, (. $)^{\mathrm{a}}=\mathrm{P}$-value Source: Author's computation, Study Data, 2018 